\title{
Job satisfaction as a matter of time, team, and trust: A qualitative study of hospital nurses' experiences
}

\author{
Lisbeth Uhrenfeldt ${ }^{* 1,2}$, Elisabeth O.C. Hall ${ }^{2}$ \\ ${ }^{1}$ Clinical Nursing Research, Aalborg University, Aalborg, Denmark \\ ${ }^{2}$ Section of Nursing, Aarhus University, Aarhus, Denmark
}

Received: September 25, 2014

Accepted: October 29, $2014 \quad$ Online Published: November 7, 2014

DOI: $10.5430 /$ jnep.v5n2p1

URL: http://dx.doi.org/10.5430/jnep.v5n2p1

\begin{abstract}
Support and variety regarding work, autonomy, organizational constraints, and promotion opportunities are factors contributing to job satisfaction or lack thereof among hospital nurses together with self-perceived health, education and career orientation. The aim of this study was to explore public hospital nurses' experiences of job satisfaction. This qualitative study was undertaken in a caring theory context. Ten proficient Danish hospital nurses were interviewed twice and data were analysed using a hermeneutic approach. The analysis revealed that time, team, and trust were essential components in job satisfaction. Time, team and trust helped the nurses collaborate with patients, care for relatives, and work in teams with other hospital staff members. Lack of job satisfaction occurred when time was to short or quality care was threatened, when the nurses felt alone and had to finish their job in a hurry, or when they perceived distrust from others about the care they provided. One one hand, these subject matters gave staff nurses a feeling of autonomy and helped strengthen their proficiency. Thus, the nurses could provide fundamental patient care in a timely and knowledgeable manner. On the other hand, lack of any of the three Ts threatened not only job satisfaction, but also patient care and nurse retainment.
\end{abstract}

Key Words: Job satisfaction, Autonomy, Qualitative, Caring

\section{Introduction}

\subsection{Job satisfaction}

Job satisfaction is connected to the clinical nurse's position in the organization, clinical grade, and the individual ward culture. ${ }^{[1,2]}$ It furthermore has significance for the understanding of the changing nature of nurses' job satisfaction, and how it links to recruitment and retention problems. Patient load, staffing level, and work responsibilities $^{[3]}$ are known as important components of nursing retention. Therefore, the purpose of this paper was to investigate Danish nurses' experiences of job satisfaction.

\subsection{Background}

Through decades, the literature documents that nurses' job satisfaction cannot be viewed homogenously; ${ }^{[4-6]}$ satisfaction and dissatisfaction emerge due to many reasons. Support and variety in work, autonomy, organizational constraint, leadership and promotional opportunities are prominent factors for job satisfaction. In addition, self-perceived health, educational work and career orientation also adds to increased job satisfaction. ${ }^{[7]}$ Climate among professionals, educational reimbursement, flexible scheduling, and higher wages are decisive factors when registered nurses (RNs)

\footnotetext{
* Correspondence: Lisbeth Uhrenfeldt; Email: lisuhr@hst.aau.dk; Address: Clinical Nursing Research, Department of Health, Science and Technology, Niels Jernesvej 14, 9220, Aalborg, Øst, Denmark.
} 
consider leaving their position or even profession. ${ }^{[8]}$ In a study examining the relationship between the number of nurses, ward organizational structure, practice and attitude towards care provision, ${ }^{[9]}$ no correlation was found between a high nurse/patient ratio and innovative nursing practice. In contrast, McGillis Hall \& Kiesners ${ }^{[5]}$ narrative interviews with hospital RNs revealed that nurses were loaded down with guilt and responsibility; commitment and the working conditions prevented them from providing the quality care they wished to perform. The RNs experienced frustration and distress due to a high number of acute admitted patients, heavy workload, time constraints and increased responsibility, often due to lack of staff. Working overtime was common and was perceived to have a negative impact on work, family life, personal health and even patient outcomes.

Near-miss and adverse event situations were investigated among novice $\mathrm{RNs}^{[10]}$ and also by expert nurses due to work overload. ${ }^{[11]}$ Findings showed that the novices needed consistent available expertise due to unpredictable workload under time constraint. Supporting novice nurses was essential for recruiting and retaining RNs and for them to provide safe quality care. Insufficient space combined with noisy surroundings are reasons for lack of job satisfaction. ${ }^{[12]}$ Further, Wethje \& Borg ${ }^{[13]}$ stress that the rate of sick leave affects the RNs' job conditions. The average sick leave in their study was 10 days per year; it was influenced by long working hours, unsatisfactory working climate, role conflicts, number of demands, expectations to repress emotions and low social support. Nearly every second RN (42\%) wanted to quit their job often due to unsatisfactory working hours and lack of professional developmental opportunities. Only $10 \%(n=2943)$ of respondents intended to stay in nursing until the age of retirement. ${ }^{[13]}$ The authors concluded that a more prominent consideration of the meaning of job satisfaction would postpone the nurses' retirement and add a qualified workforce to nursing care. ${ }^{[13]}$

Through an early critical literature review, Kennerly[14] found that both workers and administrators are challenged by the dynamic nature of healthcare systems and that they establish team-based strategies to support personal autonomy. The literature showed that shared governance and autonomy were crucial for continuous advancement of nursing practice. Likewise, in a survey measuring nurses' job satisfaction, Finn ${ }^{[15]}$ found professional autonomy to be the most important job satisfaction component closely followed by interaction, task requirements, professional status and organizational policies. However, the nurses in Finn's study felt little autonomy; instead , their activities were programmed; the RNs had too much responsibility as well as too little authority.

Given this literature data, a variety of perceptions about what constitutes job satisfaction were considered though the prominent features were style of governance and autonomy in doing the job. Likewise, job satisfaction seemed to be conditioned by staffing and patient outcomes, nurse-patient ratio, near-miss situations and ethical climates in the ward. However, the literature revealed a lack of documentation from the Nordic nurses' perspective. As the Nordic public health care system might have its special features, a study about clinical job satisfaction seemed pertinent.

The study was done in a caring theory context assuming that care is the core and moral ideal of nursing and that human beings are relational and interdependent. ${ }^{[16-19]}$

Registered nurses (RN) have been described through a stepwise development from novice to advanced beginner to competent and for some RNs to a possible higher level: proficiency. ${ }^{[20]}$ When reaching this stage, the opportunity to develop into an expert and perform with clinical wisdom seems to occur due to further experience. ${ }^{[20,21]}$ Proficiency is the main concept to explore in this study as it is significant for the RNs' clinical actions concerning expertise and clinical wisdom. ${ }^{[20-23]}$ In Benner \& Wrubels theory, ${ }^{[24]}$ caring is primarily defined as: "the alleviation of vulnerability; the promotion of growth and health; the facilitation of comfort, dignity, or a good and peaceful death; mutual realization; and the preservation and extension of human possibilities in a person, a community, a family, or a tradition. ${ }^{[24]}$ Caring as an action encompasses different strengths depending on whether the RN is a novice, competent or expert nurse, as it requires proficiency and experience to recognize patterns of significance in individual patients and act upon them in the clinical setting. ${ }^{[21]}$

\subsection{Aim and correspondence to the research design}

The aim of this study was to explore Danish hospital nurses' experiences of job satisfaction. The study took place at two hospitals in the Western part of Denmark. It was a qualitative study and the data collection method was through semi-structured interviews. ${ }^{[25]}$ To get a thorough understanding of the nurses' experiences, each nurse was interviewed twice. ${ }^{[25]}$

A hermeneutic approach ${ }^{[26]}$ of data analysis was done to understand the meaning of the clinical nurses' experiences with job satisfaction. In this approach, the nurses are understood as situated in a world of meaningful actions; they are regarded as a reservoir of knowledge and experience and supposed to be able to talk about their experiences. The key issue in a hermeneutic study is to determine meaning, significance, and importance found in each participant's response and to transform these meanings into a whole new understanding of the subject matter. ${ }^{[11]}$

\section{Method}

\subsection{Sampling procedures}

Before initiating the study, we sent a written application to the nursing executives who approved the study and for- 
warded the contact to the nurse leaders of the involved departments. The participants were contacted through their nurse leaders who had been informed of the study by the first author.

The sampling criteria for the nurses were that they were considered proficient by peers as well as by themselves and that they received an additional monthly stipend for their professional competency. ${ }^{[20]}$

By settling for this additional payment, the hospital leaders had shown that some staff members were more valuable than others. The proficiency as background for a stipend was determined by nurse leaders. ${ }^{[20]}$ Peers were asked to find those with an admirable nursing performance, and the variation in age, experience and sex was chosen by the first author. A varied sampling was intentional, ${ }^{[25]}$ and variation in jobs and experiences was sought. The goal was to get a rich material through a limited number of cases and to generate insight that could be applied well beyond the confines of the study. ${ }^{[25]}$ A total of 20 interviews were done by the first author and they took place either during or in connection with working hours and in quiet rooms close to the hospital units.

\subsection{Interview as method}

An interview style equivalent to a dialogue was used to search for the interviewees' experiences. To secure the quality of the interviews, a video-taped piloted interview was performed and analysed prior to the first interview with the RNs the piloting of the researcher's interview technique informed the researcher of some deficits such as taking appropriate breaks between questions and the need for a guided reflection framework. ${ }^{[27]}$

During the interviews, the researcher was open and listened, asked broad questions and gave the respondent proper time to answer. The participants were asked to talk about a typical day at work in details, with whom they collaborate, the impact of their job conditions on family life and how they engage in developmental work. Further, they were asked to describe episodes that made an impact on them and had shown something important about the job, and they were asked to talk about their responsibilities in clinical nursing, their actions, thoughts and feelings about issues of importance for their jobs. At the second interview, questions based on a preliminary analysis of the first interview were included and the dialogue added further understanding of the nurses' experiences. The interviews lasted from 45 to 75 minutes.

\subsection{Ethical considerations}

The study was designed following The Ethical Guidelines for Nursing Research in the Nordic Countries, ${ }^{[28]}$ and considered that the participants received verbal and written information about the study, that they did not suffer any dam- age, that the participation was voluntary and the findings were presented in an anonymous fashion.

\subsection{Data analysis}

Data were listened to, transcribed verbatim and read through several times. Data were then analysed in steps designed to produce new parts and a new enlarged whole. ${ }^{[25]}$ Following the spiral fashion of the hermeneutic circle, every step forward in the analysis was connected with the previous step in order to interpret the new abstraction in the light of the original statements. As seen in Table 1, a total of seven steps were taken before reaching a satisfactory and comprehensive interpretation that seemed to justify a new and complete understanding of the subject matter. When performing this analysis, the authors, being researchers and trained as nurses, tried to repress their theoretical and clinical preunderstanding, and to be open to what the data said about job satisfaction.

\section{Results}

In this study, the nurses' job satisfaction had recurrent patterns. We found these patterns to be matters of time, team, and trust. Positive and negative experiences of time, team, and trust were connected to the nurses' perceptions of leadership, collaboration and quality patient care, and these matters also made them consider staying in their job or getting job with less workload. In the following, job satisfaction as time, team, and trust will be elaborated.

\subsection{Sample characteristics}

Participants were ten female hospital registered nurses (RN's) working in operating theatres, outpatient departments, surgical and medical units. Adults as well as children were admitted to these wards. The participants ranged in age from 30-57 years, and had 5-32 years of nursing experience. All nurses contacted accepted participation.

\subsection{Job satisfaction and time}

Time was a factor that in one way or another shaped the working experience, the perception of satisfaction or dissatisfaction and the nurses' self-understanding. Time, whether there was lots of time or lack of time, was a matter that the RNs had to take a stand on. Time was decisive in many ways. Having enough time gave the nurses a chance to make a difference in patient outcomes, which was something they were very keen on and that made them feel good. Lack of time, on the other hand, was a matter that prevented them from reaching this goal; it made them feel unsatisfied.

Job satisfaction was present if staffing and collaboration were in order; there was time to support each individual patients' needs and time to reflect upon whether the efforts done made a difference. The feeling of being the one who 
made a difference for the patient was especially satisfying; it seemed to be related to decreased turnover. To know that we do make a difference for our patients is a solid reason to stay here." (RN 5) Having time to help patients deal with the demands from a life with chronic disease was a source of

Table 1: Steps during the analysis of transcripts

\begin{tabular}{|c|c|c|}
\hline Analysis: & Steps in analysis & Planned circular movements \\
\hline First & $\begin{array}{l}\text { Each first and second interview are read as a } \\
\text { whole; a description of every interviewee began }\end{array}$ & $\begin{array}{l}\text { Forward: characteristics of each nurse written as a statement } \\
\text { Backwards: view selection criteria and research questions to } \\
\text { deepen understanding }\end{array}$ \\
\hline Second & $\begin{array}{l}\text { Statements regarding areas of satisfaction and } \\
\text { dissatisfaction; meaningful and meaningless tasks } \\
\text { were read to investigate the content }\end{array}$ & $\begin{array}{l}\text { Forward: groups of information are developed } \\
\text { Backwards: compare statements with each nurse's specificity to } \\
\text { understand her points of view }\end{array}$ \\
\hline Third & $\begin{array}{l}\text { The purpose of the study guided the third reading } \\
\text { and the analysis progressed into a beginning } \\
\text { understanding of the coherence of the statements. }\end{array}$ & $\begin{array}{l}\text { Forward: sub-themes are emerging } \\
\text { Backwards: emerging sub-themes are evaluated as to the } \\
\text { situation they are expressed in }\end{array}$ \\
\hline Fourth & $\begin{array}{l}\text { Coherence of statements are investigated from the } \\
\text { perspective of answers in first and second } \\
\text { interview }\end{array}$ & $\begin{array}{l}\text { Forward: trustworthiness of statements are investigated } \\
\text { Backwards: coherence with individual interviewees' view is } \\
\text { evaluated }\end{array}$ \\
\hline Fifth & A structure in themes and sub-themes arise & $\begin{array}{l}\text { Forward: figures and tables are drafted to illustrate coherence } \\
\text { Backwards: re-reading original statements for validation purpose }\end{array}$ \\
\hline Sixth & $\begin{array}{l}\text { Clarifying the structure in the analysis with details } \\
\text { in interview text }\end{array}$ & $\begin{array}{l}\text { Forward: based on the analysis, transcripts are re-read } \\
\text { Backwards: second step is repeated }\end{array}$ \\
\hline Seventh & $\begin{array}{l}\text { Final step. A structure of time, team and trust is } \\
\text { established through further analysis }\end{array}$ & $\begin{array}{l}\text { Forward: findings are presented and discussed } \\
\text { Backwards: steps are evaluated to strengthen the trustworthiness } \\
\text { of the analysis }\end{array}$ \\
\hline
\end{tabular}

Lack of time made the nurses unsatisfied and distressed. Heavy bedside workload combined with a high rate of nursing students demanding teaching and learning provoked distress and unsatisfactory working conditions. Lack of time was a burden. Nurses were unsatisfied when they recognized that their patients were at risk; lack of time did not allow the patients to receive the help, attention, guidance or the basic treatment they needed. Likewise, time constraint had the potential to make the nurses inattentive. One nurse said: "Doing one task knowing you are in a hurry because two or three other tasks are waiting for you might lead to mistakes - and worse, you might not know in time." (RN 3)

The burden of too little time with patients could be related to short staffing or be caused by staff sick leave. Often the RNs found the nurse manager's demands for efficiency unreasonable; working efficiently did not always give enough time to fully concentrate on each task. The intensive turnover of patients was another reason for RN's lack of job satisfaction. Patients, who were discharged, did not have a bed and were often waiting in a chair for hours until the transportation arrived. Further, much documentation was perceived as time consuming; the time used for documentation was taken from the bedside care. One nurse said: "The nurse leaders have brought documentation of nursing care into focus. In my opinion, all this documentation is unnecessary. I bring job satisfaction. "We have cancer patients and youths suffering from intestinal diseases being prepared for surgery. Working with patients in crisis and helping them deal with new life circumstances is so meaningful, it gives me reason to stay here." (RN 7) up to 20 pieces of paper for each new patient I meet. I get angry being forced into meeting patients this way, I really would like to spend my time with patients otherwise." (RN 6)

Generally, the nurses were concerned about lack of time for quality patient care and lack of time to act professionally. One nurse said "It is so unsatisfactory if we as nurses do not have the time to act professionally and make sure that everything that needs a check-up is checked upon, that the patient is well prepared through tests or is given medicine necessary to his health." (RN 3)

\subsection{Job satisfaction and team}

Each nurse's work was generally part of a team effort to help the patient, and teamwork was a source of both job satisfaction as well as job dissatisfaction. The nurses appreciated working together; and the relationships with colleagues, patients and relatives provided job satisfaction. The staff working together also had an impact on the working spirit in the ward. A team spirit was present when the nurses expressed themselves as 'we' when talking about nurses. Working in teams helped the nurses finish their job quicker and in a satisfactory manner, while working alone made them feel that they didn't get as much work done and the quality of the work was less satisfactory. It was satisfying 
to work with a colleague or a physician they were familiar with; to manage the different situations together and to base their work on mutual reflections, experiences and understanding. Older colleagues were appreciated. The nurses worried about how to keep them in the team; they suggested fewer evening and night shifts and longer holidays.

Patients and relatives were likewise included in the team. Collaboration with patients and relatives was a meaningful part of whether a nurse felt comfortable at work. When considering leaving the job, it was seldom due to the patients "I never considered leaving because of the patients, on the contrary, they were the reason to stay." (RN 5)

When a patient arrived at the hospital and the diagnosis was fatal, the nurses included the relatives in their care. Helping the relatives through the crisis and communicating with them was described as a source of job satisfaction: "When a new patient arrives and may be dying, and if there is no contact with the patient we need to care for the relatives and make sure their pain is eased or made bearable." (RN 1)

Likewise, the team spirit helped the nurses feel caring and being cared for. Some nurses however, felt as mechanical bodies due to the overload of duties. They did the task they were told to do, offering nursing without caring. "The feeling of not being able to care, to have a dialogue or to dwell with the patients that is so unsatisfactory." (RN 3) Nurses could also blame the nurse leader for an unsatisfying care situation where the team spirit and caring was missing. "The nurse leader chose to plan this way; then she also has to bear the burden of the result." (RN 9)

\subsection{Job satisfaction and trust}

Trust was a prominent component in job satisfaction and was closely connected to how the ward was governed. The nurse leader's ability to delegate responsibility gave job satisfaction. One nurse felt trusted when having responsibility and at the same time being in charge. "I am in charge of everything around the patients' care. Our nurse leader likes to delegate responsibility. So I am quite experienced in doing this." (RN 2) Another nurse showed confidence in a newly appointed nurse leader; her future initiatives were promising: "I expect a lot from our new nurse leader. I can feel her positive intentions, she is aware of what happens in the ward or what needs to be changed. I expect her to add positive suggestions to patient care." (RN 10)

In contrast, a nurse leader who did not have strong professional objectives for the ward or did not support the staff when demands came for increased efficiency was not trusted. This type of management had a negative influence on job satisfaction; it did not improve professional development. "So far there has been shortage of time for development or initiatives and some of the staff see the nurse leader as being too weak in supporting our claims: When we try to set up new initiatives, we are always told that it cannot be afforded." (RN 2)

An uninspiring attitude about developing programs in the ward was found. Developmental educational material was described as taking a lot of effort, group work and trust in patient outcomes but the product had little relevance: "Our first step was to write a booklet to hand out to patients. We wrote down the information, we normally bring verbally. It was tested by the ward staff but it seemed as a poor improvement." (RN 4) Likewise, lack of interest in mutual goals was experienced when RNs were given the responsibility for a developmental program without having enough time to accomplish the task.

The RNs, however, expressed trust in their profession. There was a genuine belief that nursing at its best contributed to continuity of care and was important for patients; hospital nursing care was essential in itself and when considering the continuous and frequent turnover of residents. Job satisfaction also appeared when colleagues showed their appreciation and openly declared their confidence in the RNs' actions and decisions. A promising mutual goal was to help develop novice clinical nurses' personal ability in dealing with expert patients: "We prepare our new colleagues before they encounter families with specific demands. They have to learn how to deal with specific situations and issues in a professional way." (RN 9) Confidence in the development of each RN's special capability towards proficiency was seen: "Patients need nurses who can estimate their need for care; therefore, nurses have to develop this proficiency." (RN 8)

\section{Discussion}

This study investigated Danish hospital nurses' experiences of job satisfaction. Ten RNs were interviewed twice and data analysed using the hermeneutic approach. The analysis revealed time, team, and trust to be important parts of meaningful matters of job satisfaction. The themes overlap each other and are only separated for research purposes. In this study, job satisfaction was experienced as time to make a difference for the patient and to guide patients. Lack of job satisfaction occurred when there was a perceived lack of time or quality care.

\subsection{Time, team and trust}

Time is needed to form a professional judgment in each situation where the power is in possession of both parts; ${ }^{[29]}$ time allows the nurse to encounter the patient professionally with enough time for the human beings to sense, experience and be genuinely present. ${ }^{[17,30,31]}$ The nurses in our study complained about lack of time leading to decrease in the quality of care; they confirmed Martinsen's ${ }^{[17]}$ assumption that the social and instrumental time in the hospitals were dominating and contributing to a non-caring atmosphere. Time then, for better or worse, is a conditional context when caring for 
the hospital patient.

Given a rhythmic quality, time helps a conversation between the nurse and the patient to turn into a dialogue: "When the nursing dialogue is genuinely intersubjective, it has a kind of synchronicity that is evident in the nurse's being with and doing with the patient":[32-34] The nurse feels in harmony with the rhythm of the dialogue and becomes satisfied with her work. Time is not only actual time; it is connected to patient care, leadership and nursing as a profession.

Our findings about lack of time suggest that Nordic nurses share some of the same experiences regarding the influence of time on their job satisfaction, as has been identified among nurses in the United Kingdom. ${ }^{[33]}$ In that study, the UK nurses felt, to a great extent, overworked. They lacked time to perform nursing tasks i.e. addressing patient's anxiety, fear, or concern. The nurses experienced aggressive behaviour from patients and/or relatives, as well as other staff members. It seems that when nurses disperse their time, it causes distress to their surroundings and initiates a vicious circle. $^{[33]}$

In our study, job satisfaction was closely related to working in teams with staff and nurse leaders, collaboration with patients, and care for relatives. The RNs demonstrated team spirit. Our findings concur with earlier studies of teambuilding as contributing to professional development and job satisfaction as well as to the quality of care. ${ }^{[21,34]} \mathrm{A}$ caring working community helps knowledge development to flourish. ${ }^{[35]}$ Fitzgerald and colleagues' ${ }^{\text {[36] }}$ concern was that as long as "we believe that what we espouse is what we practise, we will perceive no need for review or change". They intended to inform nurses of the differences between espoused philosophy and how they spend their time at work. Our concern is for nurse leaders to work in teams and involve ward nurses in addressing the important developmental task of, through an open testing of daily habits, making choices and having preferences, for colleagues to work in teams about their priorities and to prevent turnover caused by lack of individual job satisfaction.

More than time and team, job satisfaction in our study encompassed trust. Trust was a future-oriented confidence and had both personal and mutual aims. Trust, in a caring theory context is, described as related to nurses' presence at bedside, their use of language through their choice of words, their tone, silence and body language ${ }^{[19,29,30]}$ but also how trust can turn into distrust. ${ }^{[37,38]}$ Trust in our study was related to responsibility. Our findings about trust confirm earlier findings among Nordic nurses' responsibility among proficient nurses clinical wisdom and among caring leaders. ${ }^{[23]}$ To declare confidence in other nurses' actions and decisions and thereby to be trusted as a responsible person is a kind of support where relationship between colleagues is build which is known to support job satisfaction. ${ }^{[8]}$ Thus responsibility in our study is a positive trait in job satisfac- tion.

Further, trust in this study was connected to autonomy. When a nurse was delegated responsibility and was "in charge with everything around the patient care", the nurse's work was based on self-management and done with satisfaction. This seems in line with Mrayyan ${ }^{[39]}$ who found that supportive management increases nurses' autonomy while autocratic management and workload are factors decreasing nurses' autonomy. Our study confirmed this; time constraints and workload could make a nurse feel like "a mechanical body" doing the job in a far from caring fashion. In a time where caring is widely declared to be the core of nursing ${ }^{[24,31,40]}$ or the moral ideal of nursing, ${ }^{[18]}$ nursing is developing as an independent practice discipline. It is not surprising that nurses feel frustrated, distressed and unsatisfied when patient care suffers due to lack of time, team, and trust. The nurses of this century know that nursing has independent tasks fundamental to patient care. It is clear that job satisfaction is closely linked to the feeling of autonomy.

\subsection{The trustworthiness of the study}

The trustworthiness in the areas of credibility replaces the discussion of validity and reliability in quantitative studies. ${ }^{[41-43]}$ Credibility has to do with the confidence of truth. In this study, credibility was achieved through interviewing each respondent twice, thus giving a prolonged engagement. In the second interview, the participants showed a more open, relaxed and informative attitude towards the interviewer's questions, and an in-depth understanding of the interviewee's perspective was gained. This was enhanced by regularly substantiating the interpreted text with quotes of the nurses' experiences.

Assessing dependability can be in areas such as a stepwise replication. ${ }^{[44]}$ Our study provides dependability through a table of the stepwise analysis and through dialogue between the researchers. The issue of transferability is linked with the generalizability of the data ${ }^{[44]}$ and a discussion of the extent to which the findings can be transferred to other groups or settings.

\subsection{Study limitations}

The study is limited to concern conditions as Danish hospital nurses experienced them; they cannot be immediately generalized to other contexts. However, the findings are systematically presented and discussed and they give a picture of how job satisfaction in a public Nordic context is experienced. The overall findings of this study suggest for nurse leaders and clinical nurses, as part of an empowerment plan, to have an open mutual attitude towards the connections between nurses' job satisfaction, their time to make a difference for patients, how this is linked with a reach for "best practice" and clinical nurses' actual possibility for autonomy. 


\subsection{Recommendations}

Based on this study, we recommend:

- Investigating how nurse leaders handle nurses' struggle to lower their administrative duties and form a professional judgment in each situation aiming for more autonomy in their patient care.

- Studying how patient care can develop and be visible as the main purpose for nurses in a time when economy is increasing and apparently is a threat to nurses' job satisfaction.

- Searching how nurses' job satisfaction is contributing to professional development and job satisfaction as well as to the quality of care.

\section{Conflicts of Interest Disclosure}

The author declares that there is no conflict of interest statement.

\section{References}

[1] Hayes B, Douglas C, Bonner A. Work environment, job satisfaction, stress and burnout among haemodialysis nurses. Journal of Nursing Management. 2013. PMID:24372699 http://dx.doi .org/1 $0.1111 /$ jonm. 12184

[2] Morrison KB, Korol SA. Nurses' perceived and actual caregiving roles: identifying factors that can contribute to job satisfaction. Journal of Clinical Nursing. 2014. PMID:24698172 http://dx. doi.o $\mathrm{rg} / 10.1111 /$ jocn. 12597

[3] Aiken LH, Clarke SP, Sloane DM, Sochalski J, Silber JH. Hospital nurse staffing and patient mortality, nurse burnout, and job dissatisfaction. JAMA: the Journal of the American Medical Association. 2002; 288: 1987-1993. http://dx.doi.org/10.1001/jama. 28 8.16.1987

[4] Tovey EJ, Adams AE. The changing nature of nurses' job satisfaction: an exploration of sources of satisfaction in the 1990s. Journal of Advanced Nursing. 1999; 30: 150-158. PMID:10403991 http://dx.doi.org/10.1046/j.1365-2648.1999.01059.x

[5] McGillis Hall L, Kiesners D. A narrative approach to understanding the nursing work environment in Canada. Social Science \& Medicine. 2005; 61: 2482-2491. PMID:15964672 http://dx.doi . org $/ 10.1016 /$ j. socscimed .2005 .05 .002

[6] Rittenmeyer L, Huffman D, Hopp LJ, Block M. A comprehensive systematic review on the experience of lateral/horizontal violence in the profession of nursing. The JBI Database of Systematic Reviews and Implementation Reports. 2013; 11(11): 362-468. http://dx.doi.org/10.11124/jbisrir-2013-1017

[7] Kovner C, Brewer C, Wu Y, Cheng Y, Suzuki M. Factors associated with work satisfaction of registered nurses. Journal of Nursing Scholarship. 2006; 38: 71-79. http://dx.doi.org/10.1111/j $.1547-5069.2006 .00080 . \mathrm{x}$

[8] Hart SE. Hospital ethical climates and registered nurses' turnover intentions. Journal of Nursing Scholarship. 2005; 3: 173-177. http: $/ / \mathrm{dx}$.doi.org/10.1111/j.1547-5069.2005.00030.x

[9] Adams A, Bond S. Staffing in acute hospital wards: part 1. The relationship between number of nurses and ward organizational environment. Journal of Nursing Management. 2003; 11: 287-292. http://dx.doi.org/10.1046/j.1365-2834.2003.00361.x

[10] Ebright PR, Urden L, Patterson E, Chalko B. Themes surrounding novice nurse near-miss and adverse- event situations. Journal of Nursing Administration. 2004; 11: 531-538. http://dx.doi.o $\mathrm{rg} / 10.1097 / 00005110-200411000-00010$

[11] Uhrenfeldt L. Leadership, job satisfaction and clinical wisdom. Dissertation, Aarhus, Denmark: Faculty of Health Sciences, Aarhus University, 2007.

[12] Murphy F. Stress among nephrology nurses in Northern Ireland. Nephrology Nursing Journal. 2004; 31: 423-431. PMID:15453234

[13] Wetje A, Borg W. Sygeplejerskers arbejdsmiljø, trivsel og helbred (SATH) (Eng.: The work environment, well-being and health of nurses). Arbejdsmiljøinstituttet, Copenhagen, Danish Nurses Organization, 2003.

[14] Kennerly S. Perceived worker autonomy: the foundation for shared governance. Journal of Nursing Administration. 2000; 30: 611-617. http://dx.doi.org/10.1097/00005110-200012000-00013

[15] Finn CP. Autonomy: an important component for nurse's job satisfaction. International Journal of Nursing Studies. 2001; 38: 349357. http://dx.doi.org/10.1016/S0020-7489(00) 00065-1

[16] Martinsen K. Omsorg, sykepleie og medisin. (Eng.: Care, nursing and medicine). Oslo, Universitetsforlaget, 1989.

[17] Martinsen K. Care and vulnerability. Oslo, Akribe, 2006.

[18] Watson J. Nursing: Human science and human care. A theory of nursing. New York, National League of Nursing, 1988.

[19] Løgstrup KE. The ethical demand. University of Notre Dame Press, Notre Dame, 1997. PMID:9227196

[20] Benner P, Tanner CA, Chesla CA. Expertise in Nursing Practise. Caring, Clinical Judgment and Ethics. Second edition. Springer Publishing Company, New York, 2009.

[21] Benner P, Hooper-Kyriakidis P, Stannard D. Clinical wisdom and interventions in acute and critical care. A thinking- in- action approach. Second edition. Springer Publishing Company, New York, 2011.

[22] Uhrenfeldt L, Hall EOC. Clinical wisdom among proficient Danish nurses. Nursing Ethics. 2007; 14(3): 387-398. PMID:17459821 http://dx.doi.org/10.1177/0969733007075886

[23] Uhrenfeldt L, Hall EOC. Caring for nursing staff among proficient first-line nurse leaders. International Journal for Human Caring. 2009; 13(2): 39-44.

[24] Benner P, Wrubel J. The primacy of caring. Stress and coping in health and illness. MenloPark CA, Addison-Wesley Publishing Company, 1989.

[25] Kvale S. Interviews. An Introduction to Qualitative Research Interviewing. London, SAGE Publications, 1996.

[26] Gadamer H-G. Truth and method. Second edition. New York, Continuum, 2004.

[27] Uhrenfeldt L, Paterson B, Hall EOC. Using videotaping to enhance the development of novice researchers' interviewing skills. International Journal of Qualitative Methods. 2007; 6(1): 36-50.

[28] Northern Nurses Federation. Ethical guidelines for nursing research in the Nordic countries. 2003.

[29] Delmar C. Tillid, magt. En moralsk udfordring. (Eng.: Trust \& power. A moral challenge). Copenhagen, Munksgaard, 1999.

[30] Martinsen K. Fra Marx til Løgstrup. Om Etikk og sanselighet i sykepleien. (Eng.: From Marx to Løgstrup. About ethics and sensuousness in nursing). Oslo, Universitetsforlaget, 1993.

[31] Martinsen, K. Samtalen, skjønnet og evidensen. (Eng.: The dialogue, the discernment and the evidence). 2005.

[32] Paterson JG, Zderad LT. Humanistic nursing. New York, National League for Nursing, 1988.

[33] West E, Barron DN, Reeves R. Overcoming the barriers to patientcentred care: time, tools and training. Journal of Clinical Nursing. 
2005; 14: 435-443. PMID:15807750 http://dx.doi.org/10.11 $11 / j \cdot 1365-2702.2004 .01091 . x$

[34] AbuAlRud RF. Job stress, job performance, and social support among hospital nurses. Journal of Nursing Scholarship. 2004; 36: 73-78. http://dx.doi.org/10.1111/j.1547-5069.2004 $.04016 . \mathrm{x}$

[35] Bakke-Erichsen, A., Øvrebo, R. Fra observatør til aktiv deltaker arbeidsfellesskapets betydning for sykepleierstudenters kunnskapsutvikling i praksis. (Eng.: From observer to active participant - The importance of the working community for the knowledge development of nursing students in practice). Vård i Norden. 2004; 24: 3641.

[36] Fitzgerald M, Pearson A, Walsh K, Long L, Heinrich N. Patterns of nursing: a review of nursing in a large metropolitan hospital. Journal of Clinical Nursing. 2003; 12: 326-332. http://dx.doi.org /10.1046/j.1365-2702.2003.00782.x

[37] Martinsen K. Fenomenologi og omsorg. Tre dialoger. (Eng.: Phenomenology and care. Three dialogues). Second edition. Oslo, Universitetsforlaget, 2003.
[38] Løgstrup KE. Kunst og etik. (Eng.: Arts and ethics.) Copenhagen, Gyldendal, 1961.

[39] Mrayyan MT. Nurse's autonomy: influence of nurse manager's actions. Journal of Advanced Nursing. 2004; 45: 326-336. http: //dx.doi.org/10.1046/j.1365-2648.2003.02893.x

[40] Eriksson K. Mot en caritative vårdetik. (Eng.: Towards a caritative caring ethics). Åbo, Åbo Akademi, 1995.

[41] Janlöv A-C, Hallberg IR, Petersson K. The experience of older people of entering into the phase of asking for public home helpa qualitative study. International Journal of Social Welfare. 2005; 14: 326-336. http://dx.doi.org/10.1111/j.1369-6866.20 $05.00375 . \mathrm{x}$

[42] Denzin NK, Lincoln YS. (ed.) Handbook of qualitative research. Thousand Oaks, CA, SAGE publications, 1994. PMID:7600288

[43] Denzin NK, Lincoln YS. (ed.). Handbook of qualitative research. Second edition. Thousand Oaks, CA, SAGE publications, 2000.

[44] Polit DF, Beck CT. Nursing research principles and methods. Seventh edition. Philadelphia, Lippincott, Williams \& Wilkins, 2004. 